\title{
Globalização, educação e diversidade cultural
}

\author{
José Marín
}

Resumo: O artigo aborda a problemática da globalização e suas consequeências na preservação da biodiversidade, a diversidade cultural e educação. As considerações apóiam-se na perspectiva histórica da ocidentalização do mundo, iniciada a partir da dominação colonial européia após o século XV. Essa dominação do etnocentrismo ocidental, atualmente justificado pela ideologia neoliberal, controla o domínio econômico e financeiro, a informação e as comunicações a partir das grandes empresas multinacionais e busca impor uma padronização cultural. Essa Globalização não tem um projeto de uma sociedade viável. Nossa análise desenvolveu-se a partir de uma reflexão intercultural sobre os relacionamentos entre o local e o global e busca compreender a Globalização dentro de aspectos diferentes e dentro de suas conseqüências. A educação, conhecida como responsável para a transmissão das visões de mundo, dos sistemas de valores e dos conhecimentos, diante do enorme desafio histórico de defender a preservação da biodiversidade e a diversidade cultural, como uma condição primária para imaginar a sobrevivência de nossas sociedades.

Palavras-chaves: biodiversidade; educação intercultural; Globalização.

Abstract: The article seeks to approach the problematic of Globalization and its consequences as to the preservation of biodiversity, cultural diversity and education. The considerations are based on a historical perspective of the westernization of the world, initiated by European colonial domination after the $15^{\text {th }}$ century. This domination of western ethnocentrism, currently justified by neoliberal ideology, controls the ecnomic and financial domains, information and communications beginning with the great multinational companies and seeks to impose a cultural standardization. This Globalization does not have a project for a viable society. Our analysis develops from an intercultural reflection on the relationships between the local and the global and seeks to understand Globalization within its different aspects and within its consequences. Education, seen as responsible for the transmission of world visions, value systems and knowledge, has the enormous historical challenge of defending the preservation of biodiversity and cultural diversity, as a primary condition for the survival of our societies.

Key words: biodiversity; intercultural education; Globalization.

José Marín é Doutor em antropologia pela Universidade da Sorbonne e é diplomado pelo Instituto de Altos Estudos de América Latina de Paris. Realizou estudos de Pós-graduação no Instituto Universitário de Estudos do Desenvolvimento e na Academia Internacional de Ecologia da Universidade de Ginebra. Entre 1989 e 2000, lecionou na Universidade de Ginebra e na Academia Internacional de Ecologia. Atualmente, colabora com diversas Universidades, instituições acadêmicas e publicações da Europa, América Latina e, na África tem colaborado com a UNESCO. jmarin@dplanet.ch

Tellus, ano 6, n. 11, p. 35-60, out. 2006

Campo Grande - MS 


\section{Inttrodução}

A ocidentalização do mundo começou principalmente com as Cruzadas e continuou com os primeiros «descobrimentos», da África e da América, realizados pelas expedições portuguesas, espanholas e européias no final do século XV.

A evangelização dos "pagãos», a civilização dos «selvagens» e o mito do desenvolvimento dos «subdesenvolvidos» e da globalização econômica e cultural atual são períodos de um mesmo processo histórico de dominação econômica, política e cultural por meio da imposição do etnocentrismo ocidental no mundo e em suas constantes redefinições de "ocidental", como a visão de mundo e o conjunto de seus sistemas de valores como universais, em relação a «os outros». A dominação cultural com as características próprias de cada período foi precedida pela dominação política e econômica.

A globalização atual faz parte de um processo histórico de dominação econômica e da expansão planetária do capitalismo. Esta época consolida-se depois da queda do Muro de Berlim em 1989 e com a dissolução da União das Repúblicas Socialistas Soviéticas (URSS) em 1991. Estes fatos simbólicos marcam o fim de um mundo bipolar e o inicio da imposição do modelo econômico capitalista no âmbito mundial. Este processo, liderado principalmente pelas grandes empresas multinacionais, implica a imposição de uma estandardização cultural, chamada também por alguns estudiosos "Mcdonalisation cultural" (Adda, 1998; Cassen, 2000; Lempen, 1999; Ramonet, 2000; Ramonet, 2001; Schiller, 2000).

Este último período, ainda não tem sido amplamente analisado em seus aspectos socioculturais. É verdade que a economia encontra-se na origem das grandes mudanças e mutações, mas a explicação econômica não é suficiente para a compreensão desse processo histórico. É pelo avanço tecnológico, produto de uma evolução mais ampla das idéias, que se realiza a maior revolução das técnicas da informação e da comunicação no domínio da cultura.

Abordamos, primeiramente, a história do etnocentrismo europeu, desde a dominação colonial e pós-colonial, que impôs a ocidentalização do mundo, épocas que antecederam à atual globalização. Tratamos, igualmente, da importância de preservar a diversidade cultural, tão necessária quanto a biodiversidade como patrimônio da humanidade; diversidade que o processo de globalização, tal como se desenvolve na atualidade, tende a uniformizar e depredar. 
Fazemos menção da educação, como base de nossa reflexão, desde uma perspectiva intercultural. A educação, assim posta, poderia ser o eixo da preservação da diversidade cultural e da criação de um espaço democrático, que torne possível o encontro e o diálogo de culturas. Atualmente, esta reflexão é fundamental para imaginar como viver a multiculturalidade que caracteriza as sociedades contemporâneas.

A perspectiva intercultural, aplicada na educação e em outros domínios das ciências humanas, refere-se à interação, à reciprocidade, à interdependência e ao intercâmbio que regem as relações entre culturas, na compreensão do mundo.

A educação, partindo dessa perspectiva, como transmissora de valores fundamentais, constitui a essência para imaginar projetos de sociedades viáveis, capazes de garantir a dignidade de que todos precisamos.

Nosso artigo tem um caráter introdutório e, como conseqüência, possui muitas limitações. Somos conscientes de que esta é uma problemática muito ampla e complexa, sobre a qual nos limitamos a contribuir com mais perguntas que respostas.

\section{A Ocidentalização do mundo}

O Ocidente inventou o progresso, o crescimento, o desenvolvimento e vive na crença bem ancorada de que seu projeto terá uma marcha indefinida e que seu objetivo constitui algo positivo em si, e contraditoriamente, ao mesmo tempo, também inventou sua queda, sua decadência e o caos (Latouche, 1989, p.129; tradução do autor).

A Ocidentalização do mundo começou no século XV com o processo histórico da colonização da África, da América e da Ásia (Latouche, 1989; Marín, 1994).

As raízes históricas da globalização econômica e cultural atual encontram-se na imposição do etnocentrismo ocidental, no qual estão presentes a visão do mundo e o modelo ocidental de sociedade, no contexto da dominação colonial e pós-colonial, como um modelo universal a imitar.

Primeiramente, os colonialismos espanhóis, portugueses e o colonialismo europeu em geral, necessitam legitimar a imposição de seus sistemas aos povos indígenas de América, da Ásia e da África. Este processo implicou a construção ideológica que permitiria «fabricar» peça por peça, a inferioridade de suas vítimas, mecanismo ideológico que serviu para justificar toda classe de injustiças. 
Denegrir o oprimido será a regra fundamental em uma escala de valores que pertence à cultura dominante, estruturada a partir da imposição d a universalidade de sua civilização, considerada como a única base para imaginar também um modelo único de visão de mundo, de sociedade, de economia, de política e de cultura.

A evangelização, no contexto americano, primeiro período da imposição do etnocentrismo europeu, começa no século XV e continua até o fim do século XVIII, época das grandes revoltas indígenas na América do Sul. O ritual da evangelização é o batismo e a instituição intermediária é a Igreja. $\mathrm{O}$ batismo permite converter o indígena, considerado pagão, em índio evangelizado.

A civilização dos indígenas constitui o segundo período do processo de ocidentalização iniciado no fim do século XVIII, depois das revoltas indígenas, conduzidas na sua maioria por indígenas escolarizados.

Os Indígenas, considerados como "pagãos», durante a evangelização, convertem-se, nos términos da dominação ocidental, em «selvagens» aos quais é necessário civilizar. O ritual do batismo será substituído pela alfabetização em castelhano ou em português, que são as línguas dominantes. A escola se converterá no instrumento da dominação colonial por excelência, já que esta instituição permite a imposição das culturas e as linguas oficiais.

A escola tem um papel fundamental na negação das identidades culturais. A única "integração" possível, proposta aos povos indígenas por meioda escola, é a aceitação da língua e da cultura dominante oficial em detrimento da diversidade cultural e lingüística real. É nesses antecedentes, que se encontram as raízes históricas do divórcio entre a sociedade real e o Estado oficial. Este desencontro entre a sociedade real e a sociedade oficial, perdura até nossos dias.

O terceiro período da ocidentalização imposto pela imposição do etnocentrismo europeu é o desenvolvimento dos «subdesenvolvidos», período veiculado pelo mito da modernidade (liberdade, justiça e visão leiga do mundo). Como afirma Alain Touraine: "O ocidente durante muito tempo acreditou que a modernidade era o triunfo da razão, a destruição das tradições, das identidades, das crenças, a colonização do vivido pelo cálculo" (Touraine, 1993).

A modernidade vai impregnar a história européia da revolução industrial do século XX, com a constituição do Estado-Nação como modelo político de Estado, inspirado na constituição do Estado-Nação na Espanha e, sobretudo, na França. Esta concepção do Estado impõe a 
defesa de uma Nação mítica, que supõe um povo com uma história, uma língua e uma cultura homogênea. O Estado-Nação, como modelo político, acaba, na realidade, negando a diversidade cultural e lingüística que caracteriza os diferentes povos que habitam os territórios declarados pelos novos Estados. Este modelo de Estado encontra-se na origem de muitos conflitos em diversos países do mundo atual.

Na pretensão do Estado-Nação, como modelo político, de querer hegemonizar os povos de uma maneira autoritária, encontram-se as raízes dos problemas contemporâneos e a raiz dos conflitos étnicos e religiosos não resolvidos que acabam com a África, América, a Ásia e a Europa de nossos dias.

A modernidade, no sentido europeu, tem sido considerada como a via para se conseguir a liberdade, a justiça e o direito em uma sociedade mais democrática. No contexto da América Latina e, sobretudo dos países africanos e asiáticos surgidos da dominação colonial, a modernidade transforma-se em utopia. No final do século XIX, e à diferença da Europa, a modernidade limita-se a uma proposição ideológica, a modernização, não é mais do que uma declaração política esvaziada do seu conteúdo histórico, para legitimar a expansão do capitalismo dependente, como a realização do mito do progresso (Marín, 1994). Este mito vai criar falsas oposições entre o moderno e os conhecimentos adquiridos das culturas tradicionais; entre a cultura escrita e a cultura oral e vai acabar destruindo um patrimônio cultural coletivo importante.

Os estragos provocados pelo mito do progresso também não têm preservado os países industrializados que se encontram na origem deste mito. (Houtart, 2000; Lempen, 1999; Marin, 1995; Montoya, 1992; Quijano, 1988; Touraine, 1993).

Enunciados como o mito do progresso, do desenvolvimento, do crescimento econômico indeterminado, da globalização e da nova economia, estão hoje em dia, confrontados aos desafios propostos pela ética, a dignidade humana e a problemática da ecologia. Na concepção ocidental, a dimensão ecológica estava ausente, o que explica o vazio em que nos encontramos na atualidade.

A concepção ocidental surge do divórcio entre a economia e a natureza. Atualmente, estamos obrigados a levar em conta a dimensão ecológica em todas as esferas do pensamento e da atividade humana (Costa, 2000; Ki-Zerbo, 1994; Marín, 2000; Narby, 1995).

A visão ocidental do mundo está baseada principalmente sobre a dimensão do tempo racional que determina a importância da produtividade e a rentabilidade, sem levar em conta a natureza, espaço fundamental nas 
culturas tradicionais. A natureza, nessas culturas, ocupa um lugar essencial em sua visão de mundo, sua concepção e sua maneira de viver.

A escola oficial, tal como existe em nossos países, tem veiculado a imposição de toda esta concepção ocidental, que privilegia a cultura escrita em prejuízo da cultura oral e aos conhecimentos das culturas tradicionais. O processo de ocidentalização do mundo impôs igualmente as falsas oposições entre modernidade e tradição, entre cultura oral e cultura escrita e tem privilegiado um tipo de inteligência e uma maneira determinada de construir o conhecimento. Processo de exclusão, que acabou por sacrificar um enorme patrimônio cultural coletivo.

Os conhecimentos do saber oficial institucionalizado pela cultura dominante compreendem apenas um pequeno território do saber real. Toda a riqueza dos conhecimentos da vida cotidiana, que fazem parte da educação tradicional, por exemplo, foi excluída pelas instituições da cultura oficial impostas pelo ocidente.

Antes, a modernização e, hoje em dia a globalização, impõem um "modelo de cultura única", atrás da qual, todos os povos devem alinharse, sem nenhum respeito pela diversidade cultural. Nessa perspectiva, os povos indígenas e as outras culturas são considerados como atrasados e considerados um obstáculo para a globalização do capitalismo.

A história do etnocentrismo pertence à história dos povos da humanidade. Todos os povos centram-se sobre suas próprias culturas, para se afirmar frente aos outros povos (Camilleri, 1993).

O problema começa, quando uma cultura se impõe à outra, como é o caso que tratamos. A história do etnocentrismo europeu, que surgiu a partir da conquista de América e da África, criou os implícitos culturais para legitimar a empresa colonial e pós-colonial. Um desses implícitos, ainda presentes hoje em dia e que continua exercendo influência, é aquele da universalidade da cultura ocidental.

A partir desse implícito cultural, encontramos freqüentemente a tendência a inferiorizar o saber, a visão de mundo, a concepção e o modo de vida das outras culturas. A pretendida universalidade da cultura ocidental veicula igualmente certas "verdades", concebidas sobre a base de um único modelo de sociedade induzindo as «outras culturas» a recuperar «seu atraso» com relação à sociedade ocidental. Esta concepção pertence ao determinismo cultural e faz da cultura uma entidade resistente à mudança e autônoma em suas determinações e, em conseqüência, irredutível. Esta proposição está ilustrada pelos propósitos do politólogo Samuel Huntington, quem atribui “à cultura cristã disposições para a 
democracia, tornando-a dificilmente compatível com as outras civilizações (confucionistas, muçulmanas)". Essa Tese, que não é nova, toma uma importância particular à medida que esta se opõe às perdições da modernização do mundo (Jounet, 2000, p.24-25).

O mundo está feito de uma grande complexidade e está impregnado de uma diversidade ecológica e cultural que ultrapassa largamente toda pretensão teórica reducionista, que busca impor suas verdades universais.

Nós temos que imaginar uma sociedade plural, multicultural, capaz de administrar a igualdade e a justiça na diversidade cultural, uma sociedade aberta às pluralidades e tolerante que nos ofereçam as sociedades multiculturais e que desbordem as "fronteiras culturais" e as antigas fronteiras sociais. Devemos tomar consciência das migrações, concebidas como um elemento constitutivo da história da humanidade, desde o princípio de nossa existência até os nossos dias.

Um dos grandes desafios contemporâneos é o como se viver juntos, em um ambiente de respeito entre "nós" e os "outros" no contexto da sociedade multicultural? Esta é uma pergunta, que deve ser resolvida pela educação. Nós devemos aprender a encontrar no intercâmbio e no diálogo cultural, as respostas a esta pergunta, que nos levem à eterna aprendizagem da vida, com modéstia e dignidade, longe de proposições reducionistas e de soluções simples, que não nos dão respostas à complexidade das sociedades nas quais vivemos.

A imposição dos implícitos associados à "universalidade" da civilização e da cultura ocidental, veiculados por certas Igrejas, escolas, meios de comunicação de massa pela cultura dominante, inscrevem-se na lógica da exclusão da diversidade cultural. Esta exclusão concebe-se como um instrumento da homogeneização e da estandardização cultural, buscando impor assim, um modelo único de sociedade, que se expressa nos diferentes rostos da globalização econômica e cultural do capitalismo. Estes são os traços que caracterizam a situação planetária contemporânea. Na atualidade, esse processo de expansão econômica, encontra-se bloqueado, incapaz de responder aos desafios éticos, ecológicos e às exigências para se conseguir uma real dignidade humana. Desafios, aos quais, a Globalização capitalista, órfã de um projeto de sociedade viável, não pode responder. 


\begin{tabular}{|c|c|c|c|}
\hline \multicolumn{4}{|c|}{$\begin{array}{l}\text { A VISÃO DO OUTRO NA HISTÓRIA DO ETNOCENTRISMO EUROPEU } \\
\text { O CASO DA DOMINAÇÃO COLONIAL E PÓS-COLONIAL DA AMERICA } \\
(1492-2001)\end{array}$} \\
\hline \multicolumn{4}{|c|}{ ESTADO COLONIAL } \\
\hline $\begin{array}{c}1492 \\
\text { SÉCULO XVI }\end{array}$ & $\begin{array}{l}\text { ÍNDIOS «PAGÃOS » } \\
\text { Origem biológica } \\
\text { duvidosa }\end{array}$ & $\begin{array}{l}\text { EVANGELIZAÇÃO } \\
\text { BATISMO } \\
\text { IGREJA }\end{array}$ & $\begin{array}{c}\text { ÍNDIOS } \\
\text { "EVANGELIZADOS" }\end{array}$ \\
\hline \multicolumn{4}{|c|}{ ESTADO-NAÇÃO (Repúblicas Pós-coloniais) } \\
\hline $\begin{array}{l}\text { SÉCULOS } \\
\text { XVIII A XX }\end{array}$ & $\begin{array}{l}\text { ÍNDIOS SELVAGENS } \\
\text { (biologicamente e } \\
\text { culturalmente } \\
\text { inferiores) } \\
\text { CULTURA ORAL } \\
\text { (DIALOGO E } \\
\text { PARTICIPAÇÃO) }\end{array}$ & $\begin{array}{c}\text { ALFABETIZAÇÃO } \\
\text { Em Língua e cultura } \\
\text { dominante } \\
\text { ESCOLA - } \\
\text { CULTURA ESCRITA }\end{array}$ & $\begin{array}{c}\text { INDIOS } \\
\text { "CIVILIZADOS" }\end{array}$ \\
\hline \multicolumn{4}{|c|}{ ÉPOCA MODERNA } \\
\hline $\begin{array}{l}\text { SÉCULO } \\
\text { XX }\end{array}$ & $\begin{array}{l}\text { POPULAÇÕES } \\
\text { "Tradicionais" } \\
\text { subdesenvolvidas }\end{array}$ & $\begin{array}{c}\text { MODERNIZAÇÃO } \\
\text { Escola e Meios de } \\
\text { comunicação } \\
\text { (Rádio, TV, Imprensa) } \\
\text { Mito do PROGRESSO e do } \\
\text { DESENVOLVIMENTO } \\
\text { (Ciências e Tecnologias) } \\
\text { IMAGEM E } \\
\text { ORALIDADE IMPOSTA }\end{array}$ & $\begin{array}{l}\text { CIVILIZAÇÕES } \\
\text { MODERNAS } \\
\text { (Desenvolvidas) }\end{array}$ \\
\hline \multicolumn{4}{|c|}{ EPOCA CONTEMPORÂNEA } \\
\hline $\begin{array}{c}1986 \text { - } 2001 \\
\text { FIM DA GUERRA } \\
\text { FRIA e do Mundo } \\
\text { Bipolar } \\
\text { Chernobyl } 1986 \\
\text { Desaparição da } \\
\text { URSS } \\
\text { Geopolítica do Neo- } \\
\text { Liberalismo: } \\
\text { "O Norte, o Sul e o } \\
\text { Leste" }\end{array}$ & $\begin{array}{r}\text { MUNDIALIZ } \\
\text { ECONÔMIC } \\
\text { REVOLUÇÃ } \\
\text { NA INFORMAÇÃ } \\
\text { Televisão, Ir } \\
\text { CULTUR } \\
\text { CRISES DA } \\
\text { CRISES DA SOC } \\
\text { DESAFIOS ECOL } \\
\text { BIOC } \\
\text { RECESSÃO ECONÔM } \\
\text { Que mode }\end{array}$ & $\begin{array}{l}\text { ÃO DO MODELO } \\
\text { CAPITALISTA } \\
\text { TECNOLÓGICA } \\
\text { AS COMUNICAÇÕES } \\
\text { rmática, Internet } \\
\text { DA IMAGEM) } \\
\text { ODERNIDADE } \\
\text { DADE OCIDENTAL } \\
\text { GICOS, ÉTICOS E EM } \\
\text { NÉTICA } \\
\text { A - Intolerância e Racismo } \\
\text { de sociedade? }\end{array}$ & $\begin{array}{l}\text { AUSÊNCIA DE UM } \\
\text { PROJETO DE } \\
\text { SOCIEDADE VIÁVEL }\end{array}$ \\
\hline
\end{tabular}




\section{Globalização e diversidade cultural}

A industrialização da cultura e os limites da uniformização planetária. Neoliberalismo e Globalização.

Houve uma época em que as decisões econômicas correspondiam às necessidades dos grupos sociais envolvidos. Isto ocorria, quando as comunidades solidárias constituíam a regra e não a exceção. Este processo de decisão, fundado sobre o imperativo das necessidades sociais, deixou progressivamente o lugar a uma eficiência fria e cega guiada por um sistema econômico em que o valor essencial é o benefício financeiro (Houtart; Polet, 1999, p.5; tradução do autor).

O neoliberalismo, como fundamento ideológico da Globalização, nasce depois da Segunda Guerra Mundial, na Europa do Oeste e na América do Norte. Esta ideologia traduz uma reação teórica e política, contra o intervencionismo estatal e o Estado social.

Em 1944, Friedrich August von Hayek publica The Road to Serfdom (traduzido como o Caminho para a Servidão). Esta obra constitui, em certa maneira, a carta de fundação do neoliberalismo. É um ataque apaixonado, contra as limitações que exerce o Estado sobre o funcionamento do livre mercado.

Estas travas são denunciadas, já que as mesmas constituem, em sua opinião, uma ameaça mortal contra a liberdade econômica e política. Esta obra inscreve-se no contexto histórico e político inglês, no qual o objetivo imediato é o Partido Operário, no contexto das eleições da época (1945) (Houtart; Poulet, 1999).

Em 1947, nos momentos em que os fundamentos do Estado-social se colocavam em prática na Europa de pós-guerra, Hayek convoca os que partilham de sua orientação ideológica a Mont Pèlerin, cidade próxima a Vevey, na Suiça. Entre os célebres participantes desse encontro, não somente encontramos os adversários determinados do Estado Social na Europa, como também, os inimigos declarados do New Deal americano.

No final desse reencontro, é fundada a Sociedade de Mont Pèlerin, espécie de Fraternidade neoliberal, bem organizada e consagrada à divulgação de suas teses, difundidas por intermédio de reuniões internacionais regulares.

O objetivo é duplo: por um lado, combater as medidas de solidariedade social que prevaleciam depois da Segunda Guerra Mundial e, por outro, preparar, para o futuro, os fundamentos teóricos de outro tipo de capitalismo, forte e liberado de toda regra.

Em 1974, o conjunto de países capitalistas desenvolvidos ingressa em um profundo processo de recessão. Por causa destes fatos, as idéias 
neoliberais começam a ganhar terreno. F. A. von Hayek e seus discípulos, afirmam que as raízes da crise se encontram no poder excessivo dos sindicatos e, de maneira mais geral, no movimento operário. Segundo eles, os sindicatos têm sabotado as bases do acúmulo e de investimentos, por meio de suas reivindicações salariais e suas pressões sobre o Estado, para que incremente sem cessar seus gastos em orçamentos sociais parasitários. A estabilidade monetária deve constituir o objetivo supremo de todos os governos. Neste objetivo, uma disciplina orçamentária é necessária, acompanhada de uma restrição das despesas sociais e da restauração de uma Taxa denominada «natural» de desocupação, afirmação que se traduz na criação racional de uma «reserva de trabalhadores» que permita debilitar os sindicatos. Entre outras medidas, recomendam uma redução de impostos sobre seus ganhos e sobre os ganhos mais elevados e sobre os benefícios de suas sociedades (Houtart; Polet, 1999).

Este conjunto de medidas tem deformado, de maneira desastrosa, o curso normal do acúmulo do capital e do livre funcionamento do mercado. Segundo esta teoria, o crescimento voltará naturalmente, quando se consiga a estabilidade monetária e quando forem reativadas as principais medidas (desfiscalização, limitação dos encargos sociais, desregulamentação, etc.).

Este programa não foi realizado de um dia para outro; foi necessário um decênio para impô-lo. Em 1979, surgiu uma nova situação política. Nesse ano, na Inglaterra, se iniciou o governo de Margaret Thatcher. Esse é o primeiro governo de um país capitalista avançado, que se comprometeu publicamente a pôr em prática o programa neoliberal com as conseqüências desastrosas que conhecemos hoje, no domínio da política social, da saúde e da educação pública.

Ronald Reagan foi eleito presidente dos Estados Unidos em 1980 e o neoliberalismo transformou-se na ideologia política do poder, com as conseqüências planetárias que conhecemos. Em 1982 foi a vez da Alemanha e em 1982-1984 da Dinamarca, símbolo do modelo escandinavo do Estado - Previdência.

A hegemonia de uma nova direita na Europa e na América do Norte encontra-se consolidada. É assim que no curso dos anos 1980, assistimos ao triunfo incontestável da ideologia neoliberal nos países capitalistas avançados. As conseqüências sociais podem traduzir-se nas altas porcentagens de desemprego, na diminuição das greves, em uma legislação anti-sindical e na diminuição significativa ou na supressão de importantes gastos sociais. Outra característica importante foi a privatização de numerosos 
setores econômicos, que antes eram públicos. Nos Estados Unidos, onde não existe nenhum Estado-Social similar aos da Europa, o governo dá preferência aos gastos militares, reduzindo os impostos em favor dos ricos. Os setores públicos da saúde, do social e da educação são os setores menos favorecidos. Os governos social-democratas aplicaram também os princípios do neoliberalismo, contrariamente a suas teorias políticas de origem.

Do outro lado do mundo, na Austrália e na Nova Zelândia, o esquema neoliberal está sendo aplicado com brutalidade. Nova Zelândia representa com certeza, o caso mais extremo. O Estado-social está desarticulado de maneira mais radical que no caso da Grã Bretanha.

No Chile, a experiência neoliberal está associada à influência norteamericana e teve como mentor Milton Friedman, professor na universidade de Chicago. A experiência chilena pressupunha a abolição da democracia e o começo de uma das ditaduras mais cruéis, depois da guerra. Se o Chile representa a experiência piloto para o neoliberalismo na região, a América Latina tem servido também como terreno para a experimentação dos planos que foram aplicados um pouco mais tarde, nos países do leste europeu, como Polônia e Rússia, depois da Bolívia, em 1985. Polônia e Rússia conheceram e sofreram a imposição do plano de Reajustamento estrutural. A mudança de direção rumo a um neoliberalismo se perfila na América Latina, em 1988, no México, na Argentina e na Venezuela, e finalmente, em 1990, com a eleição de Fujimori no Peru. Nenhum desses governos deu a conhecer a seus cidadãos, antes de serem eleitos, o conteúdo das políticas econômicas que tinham planejado aplicar. Carlos Mennen na Argentina, Carlos Andrés Pérez na Venezuela e Alberto Fujimori no Peru, prometeram exatamente o contrário das medidas anti-populares, que eles aplicaram depois nos anos seguintes. No México, a tradição autoritária do Partido Revolucionário Institucionalizado (PRI) é amplamente conhecida.

Das quatro experiências, três conheceram um sucesso imediato contra a grande inflação - México, Argentina e Peru - e um fracasso, Venezuela. A aplicação de medidas econômicas, tais como a desregulamentação brutal e as privatizações, provocou o crescimento do desemprego e um crescimento das desigualdades e injustiças sociais, no contexto do autoritarismo e da corrupção política. O caso do Peru é um exemplo nefasto desse período. Esse tipo de autoritarismo político não pôde ser aplicado na Venezuela.

Seria errôneo concluir que na América Latina, somente os regimes autoritários podem impor as políticas neoliberais. Os casos da Bolívia, do 
Brasil e do Equador, mostram esta evidência: a enorme inflação, com o efeito perverso da pauperização gerado cotidianamente sobre uma grande parte da população, consegue fazer aceitar ou resignar-se à mesma. As medidas brutais da política neoliberal, ainda quando preservam formas «democráticas» incipientes, provocam resultados sociais catastróficos, como é o caso atualmente, de muitos países da Ásia, da África e da América Latina.

\section{A Educação e a ideologia Neoliberal}

“Um pensamento não tem nenhum valor, se não entra no mercado" (Milton Friedman, apud Longo, 2001, p. 74).

A ideologia Neoliberal, no que se refere à educação, opõe-se fundam entalm ente aoEstado educador ou a toda filosofia política que dê ao Estado o papel prioritário na educação pública. A tendência é privatizar a educação para reduzir as despesas estatais no domínio público. A educação, nessa perspectiva, converte-se em mais uma mercadoria e essa premissa tem se convertido em uma realidade em muitos países, onde se impôs a ideologia Neoliberal.

Se revisarmos as diferentes concepções filosóficas do Liberalismo e do Neoliberalismo com relação à educação, poderíamos fazer uma breve recapitulação, como a realizada por Teresa Longo (2001).

Segundo Condorcet, representante do Liberalismo no projeto da Constituição francesa de 1793, proclama o direito dos cidadãos à instrução. A igualdade será uma declaração formal, na medida em que subsista $o$ acesso desigual ao saber. A educação pública é a base da construção de uma democracia. Condorcet escreve:

A educação é um meio para exercer os direitos e para estabelecer entre os cidadãos uma igualdade de fato e de conceder uma real igualdade política. Sobre uma base leiga... o objetivo da instrução não é o de admirar uma legislação já feita, mas fazê-los capazes de avaliá-la e corrigi-la (Longo, 2001, p. 25).

A aquisição de conhecimentos e o tema dos valores interessam a Condorcet, como afirma Badinter: "se Condorcet propõe os fundamentos da democracia social, seu projeto não é, portanto, socialista. Sua concepção da sociedade permanece fundamentalmente individualista e liberal (Badinter, 1988).

Para Jules Ferry, o conhecimento está sempre subordinado à moral. A educação consiste em adquirir um corpo de disciplinas que o Estado 
tem considerado como prioritárias e que possuem, sobretudo um valor educativo, pela adesão de todos aos valores da República. O que interessa a Ferry é o desenvolvimento do Estado-Nação; e a instrução pública é o meio privilegiado para sua construção (Longo, 2001).

Para um dos mentores do Neoliberalismo como Karl Pooper, o Estado não deve intervir na educação pública, porque impõe sua verdade, impedindo a crítica e a reflexão. No centro dos interesses de Popper está o desenvolvimento de um espírito crítico na esfera privada. Para Popper, não somente o Estado não deve educar os cidadãos, mas também não deve ocupar-se da formação da classe dirigente.

Auguste Von Hayek foi o fundador da Sociedade de Mont Pelerin (Suíça) em 1947, que reunia um grupo de intelectuais liberais da Europa e da América, do qual fazem parte Popper e Friedman, o professor de economia da Escola de Chicago, que com sua equipe, foram os ideólogos na aplicação do Neoliberalismo às políticas governamentais do Chile na época da ditadura de Pinochet.

Para A. Von Hayek, o Estado deveria encarregar-se de vigiar a ordem. Concebe um Estado guardião que tem como função garantir o sistema de poder, sem possuir finalidades políticas, sociais nem culturais. O Estado não deve intervir na educação, mas pode ao contrário ajudar as famílias pobres, para que todos tenham acesso ao direito a uma educação de base. O Estado só deve garantir o financiamento da educação de base por um sistema de bônus. Dessa maneira, os pais são livres de inscrever seus filhos na escola privada de sua escolha. Em sua concepção, a educação secundária e universitária deve ser paga, mas pode ser obtida por um crédito ou como um investimento (Longo, 2001, p. 41-65).

A ideologia Neoliberal reduz a educação a mais uma mercadoria no grande supermercado da globalização com um sistema de valores de competitividade, pragmatismo, utilitarismo e rentabilidade, fundamentos do paradigma individualista.

No caso de América Latina, a aplicação do Neoliberalismo como filosofia na educação tem uma excelente referência prática no caso chileno, que tem sido estudado detidamente por Teresa Longo (2001), quem faz algumas proposições:

Os projetos politicos seguem as idéias filosóficas em sua aplicação a programas educativos. O caso do Chile, desde a imposição da ditadura de Pinochet é um bom exemplo, em um contexto histórico e de certas alianças políticas, que fizeram possível sua aplicação. 
- A concepção neoliberal rejeita a possibilidade de atribuir à cultura um papel na construção social.

- O saber e o saber fazer, nessa concepção, convertem-se em bens que se compram e se vendem.

- Rejeição da idéia de uma sociedade, como lugar onde se partilham conhecimentos e em lugar da construção de decisões políticas.

- A educação no sentido amplo e a instrução como uma de suas formas não constituem direitos do cidadão. Pertence às famílias, instituições naturais por excelência, separar a educação de base que dá um "mínimo de educação" para o intercâmbio entre os indivíduos, garantida pelos Estados, da educação secundária e superior, como um investimento das famílias. A privatização desses níveis de educação faz parte das convicções dessa ideologia.

- O Neoliberalismo é um projeto ideológico e político moderno que concebe uma sociedade, em que toda razão de diálogo, de acordos e de convênios entre cidadãos é suprimida.

No caso Chileno e em outros países de América Latina e Europa, onde esta ideologia foi aplicada, podemos advertir que a educação pública não é mais um meio de emancipação social, como base da realização na vida social e no trabalho.

- A desigualdade e a dificuldade para ascender aos conhecimentos, à formação, criam grandes diferencias e mutações sociais, como produto de uma exclusão crescente que provoca a aplicação dessas políticas.

- A precariedade da educação pública e a pauperização de um professorado mal remunerado repercutem na qualidade acadêmica da educação pública.

- Essa pauperização provoca uma forte erosão na identidade social e na razão de ser dos professores, desprovidos da sua função social, como agentes da transmissão cultural.

- Assistimos igualmente a uma despolitização que tira a dimensão política da educação, perdendo seu sentido histórico.

Há um deslocamento perverso de uma escola que pretendia a igualdade a uma escola mercantilizada, administrada pela cegueira do mercado, com toda a carga histórica de exclusão e fragmentação social que isso supõe.

Restam nesta breve introdução algumas perguntas chaves:

Quais são os resultados das políticas Neoliberais e como têm transformado o sistema educativo? Quais são os novos sistemas de valores veiculados pela escola, sob a influência do Neoliberalismo no contexto 
histórico da Globalização? Quais são as conseqüências da privatização da educação e do enfraquecimento da escola pública?

\section{Globalização e diversidade cultural}

A industrialização da cultura está associada ao desenvolvimento econômico e à expansão dos mercados. Este processo tem suas origens nos anos 1950 (Warnier, 1999).

Todas as definições coincidem em considerar que se trata de setores que conjugam a criação, a produção e a comercialização de bens e de serviços que têm a particularidade de residir na intangibilidade de seus conteúdos, que têm um caráter cultural, geralmente protegidos pelos $d i$ reitos de autor. As indústrias culturais incluem a edição impressa e os multimídia, a produção cinematográfica, audiovisual e fonográfica. Também são consideradas nesse rubro, o artesanato e o grafismo. Certos países estendem o conceito à arquitetura, às artes plásticas, às artes do espetáculo, aos meios tecnológicos, às indústrias do esporte, à fabricação dos instrumentos de música, à publicidade e ao turismo cultural. Faz-se referência, sobretudo às indústrias criativas (creative industries). Nos meios econômicos, são qualificadas de indústrias em expansão (Sunrise industries) e nos meios tecnológicos, de indústrias de conteúdo (contenu industries) (UNESCO, 2000).

As indústrias culturais associam às obras artísticas uma sobrevalorização de caráter econômico, que gera ao mesmo tempo, novos tipos de valorização para os indivíduos e para as sociedades. A dualidade cultural e econômica dessas indústrias constitui seu sinal distintivo principal.

Qual é o papel da industrialização? Qual é o papel da industrialização da cultura atual, na preservação e na promoção da diversidade cultural, como também na democratização e no acesso à cultura? Esta é uma primeira pergunta. A segunda é: Quem controla o desenvolvimento econômico e a expansão dessa indústria, em um contexto de globalização econômica e cultural?

Durante as duas últimas décadas, o comércio internacional dos bens culturais tem se quadruplicado. Não obstante, a maior parte dos intercâmbios tem se realizado entre um número reduzido de países. Assim, por exemplo, em 1990, o Japão, os Estados Unidos de América, Alemanha e Grã Bretanha, conseguiram 55,4\% do total das exportações de bens culturais no mundo e $47 \%$ das importações foram realizadas pelos 
Estados Unidos de América, Alemanha e França. China converteu-se em 1998, no terceiro exportador mundial. Durante os anos 90, o crescimento das indústrias culturais multiplicou-se em termos econômicos e em termos de produção e distribuição (UNESCO, 2000). O caso de Walt Disney é um exemplo muito bom desta expansão. Quem controla as mensagens ideológicas e os interesses econômicos e políticos que acarreta esta Globalização ou "Disneylização" da cultura?

Quais são os direitos da propriedade intelectual dos conhecimentos tradicionais, nesse contexto de industrialização e de expansão planetária dos mercados? É uma pergunta a responder, dirigida às multinacionais. No caso da farmoquímica, é bastante conhecido o caso de pirataria dos saberes indígenas realizado por certas empresas que patentearam um sem número de plantas medicinais. Sobre esse caso, que concerne à medicina tradicional e à medicina ocidental, a Organização Mundial da Saúde, que trabalha com este terreno, tem organizado reuniões sobre o tema (OMS/WHO, 2001).

Os saberes tradicionais fazem parte das inovações e a criatividade fundadas sobre a tradição, incluído o folclore, ocupam cada dia mais a atenção dos diretivos, que decidem em setores tão diversos como a alimentação e a agricultura, o comércio e o desenvolvimento econômico, o meio ambiente, a saúde, os direitos do homem e a política cultural. $\mathrm{O}$ papel da propriedade intelectual indígena, em relação à proteção dos saberes tradicionais, tem sido o tema de uma conferência organizada pela Organização da Propriedade Intelectual (OMPI) em Genebra, em 1999 (WIPO/OMPI, 2001).

\section{A diversidade cultural}

O planeta onde vivemos está caracterizado por sua biodiversidade, constituída por uma imensa variedade de formas de vida, desenvolvidas desde milhões de anos. A defesa desta biodiversidade parece-nos indispensável à sobrevivência dos ecossistemas naturais, que formam a base dos "ecossistemas culturais", compostos de um mosaico complexo de culturas que também necessitam da diversidade para preservar o patrimônio biológico e cultural das gerações futuras.

Este eixo entre natureza e cultura e sua preservação é fundamental para nossa sobrevivência. É nesta diversidade que se encontra a riqueza de nossa humanidade. As raças bio-geneticamente não existem; nós pertencemos à mesma espécie; nós somos todos parentes e, ao mesmo tempo, 
somos todos diferentes (Langaney; Van Blijemburgh; Sánchez-Mazas, 1992).

Em 1992, a UNESCO insistiu na necessidade de realizar esforços para assumir os desafios do desenvolvimento e promover a diversidade das culturas. Esta proposição foi retomada pela Conferência Inter-governamental sobre as Políticas Culturais para o Desenvolvimento, realizada em Estocolmo em 1998.

Por ocasião da preparação da Reunião ministerial da Organização Mundial do Comércio (OMC) em Seattle, a noção de diversidade cultural foi novamente evocada, em relação aos bens e serviços culturais. Nesta reunião, sustentou-se que só políticas culturais apropriadas podem garantir a preservação da diversidade criativa, contra o risco de uma cultura única. Só as políticas de preservação da biodiversidade podem garantir a proteção dos ecossistemas naturais e, em conseqüência, garantir a diversidade de espécies.

A diversidade cultural surge, então, como a expressão positiva de um objetivo geral que busca conseguir a valorização e a proteção das culturas do mundo, diante do perigo da uniformização. Nessa perspectiva, a exceção cultural representa, de fato, um dos meios entre outros, que podem conduzir à proteção e o estímulo à diversidade cultural. Um elemento chave deste raciocínio reside na afirmação de que os bens e serviços culturais (livros, discos, jogos, multimídia, filmes e o audiovisual) não são comparáveis a outras mercadorias e serviços. É por esta causa que merecem um tratamento diferente ou excepcional que os proteja da estandardização comercial, aquela que caminha paralelamente ao consumo de massas eàs economias de escala, ligadas à indústria cultural (Adorno; Horkheimer, 1998).

Na atualidade, a cultura de massas triunfa, em particular aquela que se impõe nos grandes meios de comunicação, na televisão e na publicidade, reforçando a homogeneização do planeta, destruindo os particularismos nacionais em proveito do modelo americano (Ramonet, 1997; Schiller, 2000).

A estandardização cultural traduz-se pela americanização dos costumes, que caracterizam uma maneira de viver, de produzir, de consumir, de se vestir, de comer e de esbanjar. Nós estamos vivendo na atualidade, mais um capítulo do processo histórico da ocidentalização do mundo, iniciada pela Europa no século XV. Atualmente, a americanização é o aspecto mais grotesco e o mais caricaturizado deste processo, no qual, o sistema capitalista em sua expansão, transforma tudo o que toca em mercadoria, em sua passagem do desenvolvimento industrial para a 
industrialização da cultura. Este processo foi iniciado nos anos 1950, com a industrialização cultural que «estandardiza» tudo o que assimila, muito similar aos processos de urbanização desmedida que desintegram as antigas comunidades e atomizam as pessoas, despersonificando-as de suas existências, no meio de "a turba solitária», como afirma Edgar Morin, em seu livro: "Terre Patrie" (Morin, 1992; Ramonet, 1997).

A ocidentalização do mundo que se traduz na destruição cultural de grandes espaços geográficos, como resultado da dominação cultural do colonialismo e do pós-colonialismo, bate, hoje em dia, nas portas e nas praças de Europa, em uma viagem simbólica de regresso às fontes da história da imposição em outros territórios e em outras épocas, de valores supostamente universais, originados na mesma Europa. Este processo de imposição do etnocentrismo europeu, que corrompeu e arruinou tantas culturas no mundo, é atacado atualmente pela americanização que «invade» seu território.

A Europa atual está confrontada a uma crise de identidade, os cidadãos encontram-se desprovidos de suas indispensáveis referências culturais tradicionais, «desidentificados» enfrentam a crise atual, em um contexto de mutações e de inovações tecnológicas às quais devem adaptarse. A globalização econômica e cultural desestabiliza o conjunto das atividades econômicas e culturais, com a emergência das novas tecnologias, como a televisão numérica, os vídeo-game e a Internet. Os bloqueios culturais que provocam todas estas mutações, debilitam e põem em discussão os valores e as referências das sociedades tradicionais (Ramonet, 1997).

Como proteger os valores ancestrais da diversidade cultural da esmagadora estandardização cultural? Que responder a esta pergunta? A história lembra-nos que estes conflitos culturais não são novos. Já em épocas anteriores da história da humanidade, documentos relatam que durante os séculos XV e XVI, a confrontação entre a cultura greco-latina e a tradição judaico-cristã traduziu-se em um grande confronto cultural. O Renascimento testemunha, igualmente, os confrontos entre a fé e a razão e a verdade lógica, como resultado da dedução, que vai se opor à verdade dogmática. A emergência do pensamento racional favorece a distinção entre filosofia e religião, entre humanismo e cristianismo. $\mathrm{O}$ humanismo faz do homem o sujeito central do universo, base da concepção antropocêntrica, que marca a visão ocidental do mundo e que fixa a separação entre o homem e a natureza. Atualmente, a defesa da diversidade cultural precede a defesa da diversidade biológica. 
O estabelecimento das fronteiras arbitrárias entre humanidade e animalidade funda as raízes históricas do divórcio entre a natureza e a cultura, eixo do desafio ecológico contemporâneo.

Na visão de mundo antropocêntrica, o homem possui a vocação de submeter e dominar a natureza com resultados catastróficos que conhecemos atualmente. É sob estes fundamentos que têm sido construídas a ciência e as tecnologias e levado a humanidade de Nagasaki e Hiroshima a Tchernobyl; e com as modificações produzidas pela biogenética prometem perverter os frágeis equilíbrios dos ecossistemas, necessários para a sobrevivência de nossa espécie.

Por outro lado, o racionalismo ocidental alcança seu amadurecimento político, ao formular a Declaração dos Direitos Humanos e desencadeia, na segunda metade do século XVIII, a revolução americana e a revolução francesa. Mas a tirania da razão pode também produzir seus monstros. O Terror, sob a Revolução francesa, aparece como a expressão da intolerância da razão, da mesma forma que a Santa Inquisição foi o produto da fé (Ramonet, 1997).

O triunfo do racionalismo europeu vai significar para os outros povos da Terra uma catástrofe cultural, com a desvalorização de suas línguas e de suas culturas. A pretensão universal do sistema de valores da cultura ocidental implica a negação e a destruição das outras culturas, depois da evangelização, desde o século XV até nossos dias.

Na própria Europa, a racionalidade técno-científica e as aberrantes racionalizações políticas têm forçado os Estados à realização de massacres abomináveis durante as últimas duas Guerras Mundiais. As piores regressões do espírito humano como na África do Sul, Auschwitz, no Holocausto judeu, o GULAG russo ou a purificação étnica nos Balkanes e o massacre dos Curdos. Fatos silenciados em seu tempo, com o apoio da Europa Ocidental e a cumplicidade dos Estados Unidos de América. Todos estes dramas históricos produzem-se em nome da razão, e em salvaguarda dos interesses da geopolítica e da ciência.

Nas últimas décadas, a emergência econômica da sociedade industrial tem permitido às sociedades industriais passar da penúria da época do pós-guerra à abundância de hoje. Este auge levou estas sociedades ao consumismo, alentadas pelos meios de comunicação que impõem o modo de vida cotidiano dominante, sobretudo a televisão, condicionando as sociedades a esse referido modo de vida. Entre «ser»e «ter e possuir», a eleição de consumir e depois existir, é uma mentalidade dominante. 
Nesse contexto, assistimos igualmente, à erosão e à destruição dos laços familiares; a um individualismo crescente, que gera comportamentos associados à competitividade, ao pragmatismo, ao utilitarismo e ao cálculo nas relações inter-pessoais, destruindo desta maneira, diversas formas de solidariedade. Todo este quadro leva paralelamente à degradação dos laços familiares. A família encontra-se confrontada à evolução dos costumes, à liberdade sexual e à erosão do sistema de valores nas sociedades tradicionais.

O individualismo, neste contexto, impõe-se como paradigma e degrada a vida coletiva, o que permite a emergência de outras formas de miséria, como a solidão que reforça uma espécie de miséria espiritual. Estamos frente a problemas novos de stress e frente a um enfraquecimento dos laços afetivos. As depreciações não são só econômicas, estas podem ser mais graves se são morais e espirituais. O progresso e a glorificação da economia, que apregoam a globalização, convertem-se igualmente, nos fundamentos de uma nova religiosidade. Ignacio Ramonet (1997) afirma que nós estamos confrontados a três tipos de crises graves: a crise econômica, a crise demográfica e a crise cultural.

\section{Conclusão}

Depois da Segunda Guerra Mundial, a cultura foi colonizada pelo comércio, como produto de sua industrialização (Adorno; Horkhaimer, 1947). Atualmente, nós avançamos rumo a uma globalização na qual o comércio desfigura a cultura, assim como a dominação financeira desgasta os governos: o "cyberespace" substitui o território e o mercado, fundamentos históricos do Estado-Nação.

Os conteúdos culturais, desta maneira, convertem-se em mercadorias, o que significa milhares de anos de diversidade cultural, desaparecidos no bosque dos supermercados. As multinacionais vendem as culturas por meio dos parques de diversões "culturais", centros de lazer, como os sido desenvolvidos por Walt Disney. O turismo e as viagens buscam igualmente converter-se de fato, em grandes indústrias "culturais" em que as culturas são esvaziadas de todo seu conteúdo simbólico. Apesar dos benefícios econômicos que todas estas atividades podem produzir, não deixam de causar estragos no âmbito cultural e também destroem o meio ambiente.

Atualmente, não podemos falar seriamente de uma globalização da cultura. Os fenômenos culturais antecedem na história da humanidade, à formação da sociedade de classes e à fundação do Estado. O processo 
de globalização em que vivemos hoje em dia limita-se à expansão planetária dos mercados denominados "culturais" (cinema), audiovisual, discos, imprensa e particularmente os diários e revistas. Como afirma justamente Jean Pierre Warnier (1999), não podemos confundir a indústria da cultura com a cultura, seria confundir alguns aspectos da comercialização da cultura com a totalidade complexa que esta representa. Seria como acreditar que a revolução tecnológica é uma realidade global, sem levar em conta que uma grande parte da humanidade, que apenas sobrevive miseravelmente, encontra-se fora desta realidade. Culturas, nas quais, a vida desde o nascimento até a morte tem outras referências, além daquelas que gravitam ao redor da tela catódica da televisão ou dos computadores. Acreditar que a ocidentalização tem se convertido em um fenômeno histórico universal é um etnocentrismo primário.

$\mathrm{Na}$ atualidade, existe um debate de fundo com duas variantes: a primeira sustenta que assistimos à erosão das culturas singulares e a segunda sustenta que a americanização caracterizaria uma possível homogeneização cultural afinada com a globalização econômica. A humanidade hoje em dia, como em outras épocas, ainda se mantém como uma máquina que "fabri$\mathrm{ca}^{\prime \prime}$ as diferenças culturais, que separa e produz mestiçagens, graças às migrações das populações portadoras das culturas. Culturas que se encontram em constante adaptação, reinventando-se e recriando-se.

A humanidade continua reestruturando as sociedades e segue elaborando a geopolítica das regiões de mercados. Estas separações e mestiçagens perpetuam as culturas existentes que são transmitidas pela tradição, localizadas, socializadas e verbalizadas tornam-se criadoras de identidades. Estas substituem a função das referências, com as quais se identificam os indivíduos e as coletividades.

As culturas fazem parte de processos históricos vivos, dinâmicos e se transformam constantemente entre a dimensão local e a dimensão global. A ocidentalização do mundo esteve sempre confrontada a uma resistência cultural criadora de rostos novos e mestiços.

A globalização econômica debilita os Estados-Nação e provoca ao mesmo tempo, a emergência e as reivindicações de diferentes identidades culturais. A comercialização da cultura tem dificuldades para estandardizar as outras culturas e para uniformizá-las, apesar de sua poderosa maquinaria tecnológica. Um dos grandes obstáculos que bloqueiam sua expansão é que uma grande parte da humanidade, por razões de precariedade econômica, não pode integrar-se aos grandes supermercados que impõem a globalização econômica no âmbito planetário. 
Atualmente, assistimos a certa resistência contra a globalização da parte de muitos setores da população civil, mas também assistimos à erosão e à destruição de certas culturas. Nesse mesmo processo, as culturas desenvolvem uma enorme diversificação e reinvenção das tradições, em sua busca de pontos de referência, necessários para suportar e sobreviver, no meio de um contexto caracterizado por suas profundas mutações e injustiças. Os Estados são desbordados pelo poder financeiro das multinacionais, incapazes de assumir seu antigo papel de intermediários políticos.

A idéia de uma cultura universal baseada em referências comuns está também bloqueada pela irracionalidade do benefício econômico que persegue os grupos econômicos dominantes, muito distantes de todo projeto coletivo e de todo interesse social. O discurso como aquele da defesa dos Direitos Humanos, em um sentido muito amplo, fica no âmbito das declarações políticas, quase sempre muito distantes da realidade.

A resistência à dominação econômica e cultural faz parte da história da humanidade. Os filósofos das Luzes, no século XVIII, criaram uma visão social filosófica de uma grande força, para coincidir com a evolução da propriedade e do mercado. Atualmente, é preciso criar uma reflexão que tenha a capacidade suficiente para que esta extraordinária revolução tecnológica veiculada pela globalização desenvolva-se a serviço da humanidade e não contra ela. Não queremos que toda nossa existência seja transformada em uma mercadoria para ser oferecida nas redes do comércio eletrônico. O exemplo de como se tem utilizado a televisão é nefasto. A utilização majoritariamente comercial deste meio nos levou a algumas aberrações, como as que, muito bem descreve, um informe do semanário norte-americano Business Week:

uma criança de 7 anos, vê uma média de 2.000 propagandas publicitárias por ano e aos 12 anos, seu nome figurará nas gigantescas bases de dados das empresas de venda por correspondência" (Schiller, 2001, p.31-32)

Imaginar a televisão, igualmente as novas técnicas da informação e da comunicação, a serviço da educação de massa, é uma utopia que deveria ser alimentada e apoiada.

O final do século XX e o começo deste século estarão marcados pela emergência de dois grandes movimentos: o respeito pela biodiversidade e a defesa da diversidade cultural em opõsição a toda destruição da natureza e à uniformização da cultura.

Os organismos geneticamente modificados (OGM), base da alimentação transgênica, têm provocado ultimamente verdadeiras catástrofes. Esta prática comercial da alimentação desnaturaliza os alimentos de suas 
referências culturais. A aplicação das biotecnologias e, em particular, a manipulação artificial do DNA, o patenteamento da vida e a clonagem de mamíferos adultos, acabarão pervertendo a cadeia alimentr e os ecossistemas, a ponto de poder ser catastrófico para nossa sobrevivência.

A globalização do capitalismo provoca a resistência e a emergência de novos movimentos sociais de contestação contra esta dominação, que também é cultural. Um dos grandes conflitos sociais mais importantes do século XXI será a preservação da biodiversidade e da diversidade cultural.

A educação inter-cultural tem e terá nesta perspectiva um papel central, como lugar propício para o encontro e o diálogo de culturas. A educação intercultural, poderá criar as condições que tornarão possível o encontro das culturas na perspectiva de uma complementaridade benéfica para todos, além de toda hierarquização e de toda valorização unilateral.

Na situação mundial atual, depois da agressão militar imperialista contra o povo do Iraque, a perspectiva intercultural encontra-se diante de um enorme desafio: a imposição militar da predestinação geopolítica norte-americana, de um etnocentrismo e de uma visão de mundo autoritária e monocultural impregnada de um certo fundamentalismo religioso (Stemberg, 1970).

Atualmente, a educação intercultural poderia criar uma abertura a respeito da diversidade cultural, contrariamente a qualquer educação monocultural, etnocêntrica e excludente. A educação, nesta perspectiva, poderia trabalhar pela dignificação do que somos e dos valores comuns de respeito, solidariedade, justiça e tolerância, com os quais nos reconhecemos e nos identificamos.

Precisamos fortalecer o respeito por nós e pelos outros, como uma fonte capaz de alimentar a dignidade de que todos necessitamos, para construir a base afetiva de nossa sobrevivência.

\section{Referências}

ADDA, J. La mondialisation de l'économie, 2 vols.; 1. Genèse; 2. Problèmes. 3. ed. Paris: La Découverte, collection "Repères", 1998.

ADORNO, T. W. ; HORKHEIMER, M. La production industrielle de bien Culturels. In: . La Dialectique de la raison. Paris: Gallimard, 1974.

ALVES, A., BRAREIRA, C., SILVA de ALMEIDA, B. J. E. (Orgs.). Origens do Totalitarismo. 50 anos depois. Rio de Janeiro: Relume Dumará, 2001. 
AMIN, S.; HOUTART, F. Mondialisation et alternatives. Genève: CETIM-AAJ-LIDLIPWILPF, 2000.

AUGE, M. Pour une anthropologie des mondes contemporains. Paris: Aubier/Critiques, 1994.

BADINTER, E. Condorcet un intellectual en politique. Paris: Fayard, 1988.

BRAUDEL, F. Civilisation matérielle, économie et capitalisme. XV-XVIIème siècle. Paris: Armand Colin, 1979.

BRUSH, S.; STABINSKY, D. Valuing Local Knowledge: Indigenous Peoples and Intellectual Property Rigths. Washington D.C.: Island Press, 1996.

CASSEN, B. La langue-dollar. In:___. L'Amérique dans les têtes. Manière de voir / Le Monde Diplomatique. n. 53. pp. 88-90, 2000.

. Les langues, ces fils d'or du combat contre la mondialisation libérale. In: $L a$ culture, les élites et le peuple. Manière devoir/Le Monde Diplomatique. n. 57, pp. 8890, 2001.

CAMILLERI, C. Le relativisme:du culturel à l'interculturel. In: TANON, F.; VERMES, G. (Eds.). L'individu et ses cultures. Paris : L'Harmattan, 1993.

CHOMSKY, N.; DIETERICH, H. La Aldea global. Tafalla: Xalaparta, 1998.

COHEN, D. Richesse du monde, pauvreté des nations. Paris: Flamarion, 1997.

COSTA, J. L'Homme - Nature ou l'alliance avec l'univers. Entre Indianité et modernité. Paris: Editions Sang de la terre. Collection La pensée écologique. 2000.

DEGREGORI, C. I. (Ed.). No hay país más diverso. Compendio de antropología peruana. Lima: PUC - Universidad del Pacífico - IEP, 2000.

DEMORGON, J. L'histoire Interculturelle des sociétés. Paris: Anthropos, 1998.

. J. L'interculturation du monde. Paris: Anthropos, 2000.

DIXON, K. Les Evangélistes du marché. Paris: Raisons d'agir Editions, 1998.

FANTASIA, R. Le système “McDo". In: L'Amérique dans les têtes. Manière de voir/Le Monde Diplomatique. n. 53. pp. 86-87, 2000.

FORRESTER, V. L'horreur économique. Paris: Fayard, 1996.

FRANK, T. “Titanic” et la lutte des classes. In: L'Amérique dans les têtes. Manière de voir / Le Monde Diplomatique. n. 53. pp. 91-93, 2000.

GAILLARD, J.M. Comment la planète est devenue un village. In L'Histoire. Dossiers: Les racines de la mondialistaion. n. 270, novembre, pp. 31-40, 2002.

HALLAK, J. Education et globalisation. Paris: UNESCO, 1998.

HOBSBAWM, E. L'Âge des extrêmes. Histoire court du XXème siècle. Paris: Editions Complexe - Le Monde diplomatique, 1999.

. Le déclin des avant-gardes au XXè siècle. In: La culture, les élites et le peuple. Manière de voir / Le Monde Diplomatique. n. 57, pp.60-65, 2001.

HOPENHAYN, M.; OTTONE, E. El Gran Eslabón. Educación y desarrollo en el umbral del siglo XXI. Buenos Aires: Fondo De Cultura Económica, 1999.

HOUTART, F.; POLET, F. (Eds.). L'autre Davos. Mondialisation des résistances et de luttes. Paris: L'Harmattan, 1999. 
HUNGTINGTON, S. Le choc des civilisations. Paris: Editions Odile Jacob, 1997.

JOURNET, N. Penser la culture. In: Sciences Humaines / Dossier. n. 110 pp.22-27, 2000.

KAMINSKI, C.; KRUK, S. Le nouvel ordre International. Paris: Coll. Que sais-je ?, Presses Universitaires de France, 1993.

KENNEDY, P. Préparer le XXI siècle. Paris: Editions Odile Jacob, 1993.

LAÏDI, Z. Un mobnde privé de sens. Paris: Fayard, 1994.

KI-ZERBO, J. (Ed.). Compagnons du soleil. Paris: FPH - La Découverte - UNESCO, 1993.

LANGANEY, A.; VAN BLIJEMBURG, N.; SÁNCHEZ-MAZAS, A. Tous parents, Tous différents. Paris: Chabaud, 1992.

LATOUCHE, S. L'occidentalisation du monde. Paris: Galma - La Découverte, 1989.

LEITE GARCIA, R. (Org.) Método, Métodos, Contramétodo. Sao Paulo: Cortez, 2003.

LEMPEN, B. La mondialisation sauvage. De la fin du communisme à la tragédie du Kosovo. Lausanne: Favre, 1999.

LONGO, T. Philosophies et politiques Néo-libérales de l'éducation dans le Chili de Pinochet 1973-1983. Paris: L'Harmattan, 2001.

MARIN, J. Dimension historique de l'ethnocentrisme européen dans le processus de domination coloniale et post-coloniale de l'Amérique. In: BLOMART, J.; KREWER, B. (Eds.) Perspectives de l'interculturel. Paris: L'Harmattan, 1994.

Ethnocentrisme et racisme dans l'histoire européenne dans le cadre de la conquête de l'Amérique et perspective actuelle. In: ALLEMANN-GHIONDA, C. (Eds.). Multicultur und Bildung in Europa. Multiculture et éducation en Europe. Bern: Peter Lang, 1994.

. Le développement durable et la dimension interculrturelle. In: GIORDAN; DENIS LEMPEREUR, J. (Eds.) 12 Questions sur l'environnement. Nice: Zéditions, 1996.

Une éducation appropriée aux peuples autochtones d'Amérique latine. In: DASEN, P.R. ; PERREGAUX, C. Pour quoi des approches interculturelles en éducation. Bruxelles: DeBoeck Université, 2000.

Histoire de l'Etat-Nation: de la politique d'intégration en Amérique Latine et en Europe. In: PERREGAUX, C. et al. (Eds.). Intégration et Migrations. Regards pluridisciplinaires. Paris: L'Harmattan, 2001.

. Globalización, Educación y diversidad cultural. Perspectiva. Florianópolis v.20 n.2, jul./dez., 2002.

. La reflexión intercultural como base para imaginar una educación democrática para los pueblos autóctonos y para la sociedad multicultutral en América Latina. Cenários. São Paulo, n.2-3. 2002a.

MATO, D., MONTERO, M., AMODIO. E. (Eds.). América Latina en tiempos de Globalización: procesos culturales y transformaciones socio políticas. Caracas: U.C.V. ALAS - UNESCO, 1996.

MONTOYA, R. Al borde del naufragio. Democracia, violencia y Problema étnico en el Perú. Lima: Cuadernos de SUR, 1992.

MORIN, E. Terre Patrie. Paris: Editions du Seuil, 1993. 
QUIJANO, A. Modernidad, Identidad y Utopía en América Latina. Lima: Sociedad y Política, 1988.

NARBY, J. Le Serpent cosmique. L'ADN et les origines du savoir. Genève: Georg, 1995. NOUAILHAT, Y.-H. Les Etats-Unis et le monde au XXème siècle. Paris: Armand Colin, 1997.

RAMONET, I. Nouveaux pouvoirs, nouveaux maîtres du monde. Montreal: Fides, 1996. . Géopolitique du chaos. Paris: Galilée, 1997.

. La culture à l'ère d'Internet. In: La culture, les élites et le peuple. Manière de

voir / Le Monde Diplomatique n. 57. pp. 6-7, 2001.

. Contrôler les esprits. In: L'Amérique dans les têtes. Manière de voir / Le Monde Diplomatique n. 53. pp.6-7, 2001a.

SANTOS, M. Por uma outra Globalização. Do pensamento único à consciência universal. Rios de Janeiro: Record, 2003.

SCHILLER, H. I. Décervelage à l'Américaine. In: La culture, les élites et le peuple. Manière de voir / Le Monde Diplomatique n. 57. pp. 29-32., 2000.

STENDU, K. Images de l'autre. La différence du mythe au préjugé. Paris: Seuil/Editions UNESCO, 1998.

STIGLITZ, J. E. Vivir el malestar de la Globalização. Buenos Aires: Taurus, 2002. . La grande désillusion. Paris: Fayard, 2002.

TORRES SANTOMÉ, J. A educação em tempos de Neoliberalismo. Porto Alegre: Artimed, 2003.

TOURAINE, A. Critique de la modernité. Paris: Fayard, 1993.

UGARTECHE, O. La Arqueología de la modernidad. Lima: DESCO, 1999.

UNESCO. Culture, commerce et mondialisation, 2000. [Texte téléchargé 2/06/2001] . Disponível em: <http://UNESCO.org/culture/industries/trade/html-fr/question 1.htm>.

WALLERSTEIN, I. Capitalisme et économie monde. Paris: Flammarion, 1980.

WARNIER, J.-P. La mondialisation de la culture. Paris: La Découverte. Coll. Repères, 1999.

WASCHTEL, N. La vision des vaincus. Paris: Gallimard, 1971.

WHO/OMS. Reportt of Inter-Regional Workshop on Intellectual Property Rights in the Context of traditional Medicine. Bangkok, Thailand: WHO/OMS, 2001.

WIPO/OMPI. Intellectual Property Needs and Expectations of Traditional Knowledge Holders. Report on Fact-finding Missions en Intellectual Property and Traditional Knowledge (1998-1999). Geneva: WIPO / OMPI, 2001.

VERBUNT, G. La société Interculturel. Vivree la diversité humaine. Paris: Editions du Seuil, 2001.

ZIEGLER, J. Les nouveaux maîtres du monde et ceux qui le résistant. Paris: Fayard, 2002.

Recebido em 15 de outubro de 2005.

Aprovado para publicação em 24 de novembro de 2006. 